\title{
LINGÜÍSTICA
}





\section{LA EXPRESIÓN FRASEOLÓGICA VERBAL EN EL DISCURSO INFORMATIVO DEL ESPAÑOL ACTUAL}

Ángel Cervera Rodríguez

\section{(c) $(1) \Theta(9)$}

Esta obra está bajo una licencia Creative Commons

Reconocimiento-No Comercial-Sin Obra Derivada 



\title{
LA EXPRESIÓN FRASEOLÓGICA VERBAL EN EL DISCURSO INFORMATIVO DEL ESPAÑOL ACTUAL
}

\author{
PHRASEOLOGY VERBAL EXPRESSION IN THE INFORMATIVE \\ SPEECH OF THE CURRENT SPANISH
}

\author{
Ángel Cervera Rodríguez
}

\begin{abstract}
RESUMEN
Este trabajo tiene por objeto delimitar el ámbito de las unidades fraseológicas y explicar el carácter lingüístico-pragmático de las expresiones fraseológicas verbales en el discurso informativo del español actual. Para la fundamentación teórica, se han tomado como referencia algunos de los estudios más relevantes sobre fraseología con el fin de diferenciar las expresiones fijas, semifijas y colocaciones. Tras la muestra de ejemplos de unidades fraseológicas verbales extraídos de diversos medios de comunicación, se ha procedido a la aplicación de los procedimientos sintácticos, léxicosemánticos y pragmáticos que operan en ellas para identificar el grado de fijeza e idiomaticidad. En definitiva, las unidades fraseológicas analizadas no solo contienen un significado literal, sino también significados adicionales adquiridos en el contexto comunicativo.

Palabras clave: fraseología, locución, colocación, enunciado fraseológico, idiomático.
\end{abstract}

\begin{abstract}
The purpose of this work is to delimit the area of the phraseological units and explain the linguisticpragmatic character of verbal phraseological expressions in the informative speech of current Spanish. For the theoretical foundation, have been taken as a reference some of the most relevant studies on phraseology in order to differentiate the fixed, semifixed expressions and placements. After the set of examples of verbal phraseological units extracted from diverse mass media, one has proceeded to apply the syntactic, lexical - semantic and pragmatic procedures that operate in them so as to identify the degree of firmness and idiomatic correction. In short, the phraseological units analyzed not only contain a literal meaning, but also additional meanings acquired in the communicative context.
\end{abstract}

Key words: phraseology, locution, placement, phraseological statement, idiomatic.

\section{Introducción}

A diferencia de la Estilística, considerada como la ciencia de la expresión, la Fraseología ${ }^{1}$ es la rama científica que se ocupa de las expresiones y frases formalizadas. El $D R A E$ (2014) la define como "Conjunto de modos de expresión peculiares de una lengua, de

\footnotetext{
Dr. Ángel Cervera Rodríguez. Universidad Complutense de Madrid. Titular de Universidad. Docente e investigador en Facultad de Filología, Departamento de Lengua Española, Teoría de la Literatura y Literatura Comparada. España.

Correo electrónico: cervera1@filol.ucm.es
}

Recepción: 20- 01- 2017

Aceptación: 04- 03- 2017 
un grupo, de una época, actividad o individuo", y como "Parte de la lingüística que estudia las frases, los refranes, los modismos, los proverbios y otras unidades de sintaxis total o parcialmente fijas". Mellado-Blanco (2004, p. 15) llega a decir que desde la época humanística la Fraseología designa tanto el inventario de expresiones idiomáticas o fraseológicas de una lengua como el estudio sobre ellas. Dicho esto, podría considerarse la expresión fraseológica como unidad léxica integrada por dos o más palabras con significado unitario y, a su vez, caracterizada por su alta frecuencia de uso, su fijación e idiomaticidad.

La lengua maneja recursos muy variados destinados a la comunicación, entre los que destaca el empleo de numerosas unidades fraseológicas (UFS). Desde hace mucho tiempo interesa a investigadores de lexicografía, lexicología, fraseología, semántica y gramática conocer el proceso de configuración gramatical y el grado de lexicalización de estas expresiones, dada la relación estrecha existente entre léxico y sintaxis, pero también el valor pragmático que adquieren en los actos de habla. Los investigadores clasifican las UFS aplicando criterios morfosintácticos y semánticos, por lo que hablan de compuestos sintagmáticos, locuciones, colocaciones y enunciados libres, aunque en general se caracterizan por su variedad significativa y configuración formal o gramatical dentro de un contexto determinado.

\section{La fraseología en el discurso informativo del español actual}

\subsection{Procedencia de la fraseología verbal en el discurso informativo}

La amplia posibilidad de acceder a la información ${ }^{2}$ permite a los lectores familiarizarse con la lengua del periodista y de insertar de manera constante palabras, expresiones y estructuras sintácticas procedentes de la lengua coloquial. Así, a través de los diferentes géneros periodísticos se van asimilando unidades fraseológicas que se convierten en fórmulas asentadas en la lengua común de la mayoría de los usuarios. Nos centraremos en el uso que hacen los medios de comunicación audiovisual, considerada como comunicación periodística que glosa mensajes de carácter informativo, narrativo, explicativo y valorativo de la actualidad con notas de novedad e interés social.

El discurso de la información y de la comunicación en general toma como base el léxico de la lengua común integrado por palabras individualizadas y expresiones fraseológicas, como se ve en 1. El Bayer de Múnich acabó con los sueños del Benfica y logró el pase a semifinales en un partido que se le puso cuesta arriba (La Razón, 14/4/16), donde los verbos "acabó", "logró" y "puso" marcan la pauta fraseológica, aunque son los sustantivos acompañantes los que producen el significado y la orientación pragmática que proyecta el locutor en el discurso. El $1^{\circ}$ responde a una UF con forma de colocación para expresar la derrota inapelable del equipo de fútbol Benfica ante Bayer de Múnich; el $2^{\circ}$ es una UF constituida con $\mathrm{V}+\mathrm{SN}$ para indicar que la victoria le abre expectativas al Bayer en semifinales, aunque se matiza que tuvo dificultades al inicio del partido a través de la $3^{\mathrm{a}} \mathrm{UF}$ también formada por $\mathrm{V}+\mathrm{SN}$.

Esto nos viene a decir que el discurso de los medios de comunicación está abierto a la incorporación de términos procedentes de códigos y de fuentes de procedencia diversa de la lengua actual. Además, la lengua cuenta con estructuras sintácticas y procedimientos de asociación y de transposición léxico-semánticas - metáfora, metonimia, personificación, hipérbole, etc.- que permiten al hablante ampliar el campo designativo y simbólico con el 
que dar a conocer e interpretar la realidad representada, como podemos ver en expresiones fraseológicas verbales con "dar", cuando funciona como verbo soporte, siguiendo a BlancoEscoda (2000), en casos del tipo: 2a. Parece que le dan ya por muerto. Sí le dedica el editorial. Rajoy "incrementa su presión sobre el PSOE y Ciudadanos para que respalden un gobierno en torno a su persona" (refiriéndose a Pedro Sánchez, Secretario General del Partido Socialista Español, tras las elecciones del 20 de diciembre de 2015) (Libertad Digital, 30/12/15), cuya expresión verbal equivale figuradamente a la idea de que ya se le ha acabado todo el crédito y el apoyo que tenía al líder del PSOE; b. Le dio un cheque en blanco porque entendía era mejor. Fruto de eso, hemos pactado con fuerzas nacionalistas como Compromís (refiriéndose a la posición del Partido Socialista del País Valenciano o PSPV) (Libertad Digital, 30/12/15), donde la expresión viene a significar también metafóricamente que hay un apoyo incondicional al pacto con Compromís; y c. Si Ciudadanos consigue regenerar a Rajoy "habrá realizado una impagable labor política”. Y al loro que no les den gato por liebre, que Rajoy es perro viejo y no te puedes fiar, que tiene mucho vicio con el ordeno y mando. (Libertad Digital, 19/01/16), donde aparecen dos expresiones fraseológicas: la $1^{\text {o }}$ es una locución o expresión verbal constituida por el verbo "dar", acompañado de dos formas nominales coloquiales "al loro", con el significado de "cuidado", y "gato por liebre" para indicar que "no les engañen"; y otra con "es (Vcop). + perro viejo (SN)", expresión verbal equivalente a "astuto", que utiliza el locutor para calificar a uno de los enunciadores 3: "Rajoy".

\section{2 Ámbito de las expresiones fraseológicas del discurso informativo}

La fraseología corresponde al conjunto de unidades fijadas que pertenecen al discurso repetido, como señala Coseriu (1986, p. 144). Se trata de «unidades pluriverbales» que se manifiestan en cualquier nivel de lengua, por lo que adquieren significado auténtico en relación con el sentido pragmático adecuado. No basta conocer el significado, sino que hay que saber por el contexto con qué sentido se utilizan, como en 3a. Ciudadanos abre la puerta a negociar con los socialistas (El Confidencial, 19/1/16); b. Pedro Sánchez no debe prometer lo que no está en su mano (La Razón, 17/1/16); y c. Garzón (Alberto) hace un guiño al PSOE para un pacto $(A B C, 24 / 12 / 15)$. En los tres enunciados se comprueba que el verbo funciona como soporte o apoyo de cada una de las expresiones verbales: en a. mediante "abre la puerta a negociar" se expresa metafóricamente la disposición a negociar; en b. a través de la construcción asertiva negativa "no está en su mano" el locutor señala que el sujeto carece de capacidad para negociar; y en c. por medio del verbo comodín "hacer" en "hace un guiño" el sujeto enunciador "Garzón" muestra el deseo de querer negociar.

La Fraseología abarca el conjunto de fórmulas diversas que el español ofrece dentro de lo que entendemos como expresiones o esquemas fijados. A su vez, designa una parte de la lexicología, ciencia lingüística que estudia las combinaciones estables de unidades léxicas formadas por dos o más palabras gráficas y cuyo límite se sitúa en el nivel de oración, según manifiesta Corpas-Pastor (1996, p. 20). A su vez, la unidad fraseológica (UF) se define como unidad léxica integrada por dos o más palabras dotadas de significado unitario. Se caracteriza por su alta frecuencia de uso, su fijación e idiomaticidad. Por ello, en el análisis de las unidades fraseológicas hay que tener presente, como señala Martínez-López (1995, p. 198), los aspectos morfosintácticos, léxico-semánticos y pragmáticos. 


\section{Expresiones fraseológicas frecuentes en el discurso informativo actual}

\subsection{Delimitación conceptual de las unidades fraseológicas}

A pesar de los numerosos estudios existentes sobre la fraseología, no hay una denominación clara y diferenciada sobre las unidades que la integran. Se utilizan términos como "unidad fraseológica, dicho, dicho popular, expresión fija, frase hecha, paremia, frase proverbial, proverbio, giro, giro idiomático, fórmula, locución, locución idiomática, modismo, refrán, adagio, aforismo, sentencia, máxima, modos de hablar, etc.", tal como se recoge en Casares (1992, pp. 163-242) y en Zuluaga (1980, p. 15). Por su parte, Ruiz-Gurillo (1997, pp. 45-47) utiliza los términos de unidad fraseológica (UF), locución y unidad sintagmática verbal (USV). No obstante, se inclina por utilizar el de UF, que hace referencia a una combinación fija de palabras que presenta algún grado de fijación y eventualmente de idiomaticidad.

En los últimos tiempos se ha pretendido aglutinar toda esta amplia terminología bajo la denominación de "unidades pluriverbales" (NGLE, 2009) y "unidades fraseológicas" (UFS), a las que atiende la Fraseología y la Paremiología. Aunque se recurre al término UF para designar las expresiones hechas y fijas, no resulta fácil diferenciar completamente los compuestos sintagmáticos, las colocaciones, las fórmulas rutinarias, las locuciones y las paremias, que, a su vez, incluye los proverbios, los refranes, los eslóganes y las consignas. Para Corpas-Pastor (2003, p. 131), las UFS se caracterizan por la unidad dada entre sus componentes como reflejo de la conciencia que tienen los hablantes de la integración de las unidades. Baste considerar expresiones del tipo 4a. Pablo Iglesias entra en el cuerpo a cuerpo contra el Gobierno (El País, 15/12/15); b. España entra con buen pie (refiriéndose a la selección de fútbol) (Marca, 25/12/15); c. Rajoy entra en campaña y promete que se acabará de trabajar a las seis de la tarde (El Confidencial, 2/4/16); y d. (Sobre Antonio Cosmen, cocinero en Vallecas) De pequeño ya le entró el gusanillo (El Mundo, 6/04/2016). Como se constata, el denominador común de las expresiones de 4 es el de la integración de un VApoyo o soporte "entrar" + SPrep. o SN; así el mismo verbo "entrar" que actúa de soporte comporta un significado y un valor semántico diferentes: en 4a. está acompañado de una locución nominal tautológica "cuerpo a cuerpo" para expresar que "se enfrenta"; en b. adquiere un valor positivo al inferir que, al ganar, hay buenas expectativas de éxito por parte de la selección; en c. se expresa que el sujeto semántico comienza la acción; y en d. se asocia con el gusto por la actividad de la cocina desde niño.

Ahora bien, las expresiones fraseológicas obedecen a la puesta en funcionamiento de las reglas que establecen relaciones sintagmáticas y paradigmáticas, como cualesquier otras unidades lingüísticas. Esto supone que las palabras se seleccionan para combinarse en la secuencia sintáctica por afinidad, asociación e implicación semántica, por operaciones de relación o atracción sintáctica, por procedimientos de transposición semántica, por herencia histórica, pero también por el uso que hacen los hablantes de estas expresiones en el acto discursivo, sobre todo en el periodístico. Por ello, cabe decir que muchas de las unidades fraseológicas están ligadas a la vida, las costumbres y a las experiencias compartidas de los hablantes. La actualización de las unidades fraseológicas viene dada por la capacidad de representar pensamientos convencionales fácilmente identificados por los alocutores (o intérpretes), como sucede en 5. En los últimos días la cúpula del partido se ha cuidado de poner sobre la mesa otras condiciones de tono más social para recordar a estos votantes que 
ellos también están por el cambio en el resto de frentes, situando al PSOE dentro del marco de quienes no desean moverse del consenso del régimen (El País, 20/12/15), donde aparece una expresión o locución verbal "poner sobre la mesa" en lugar de "aclarar o clarificar", cuyo sujeto enunciador es el partido de Podemos y otra expresión con valor de colocación "están por el cambio" equivalente a "quieren cambio".

\subsection{Posibilidad de clasificar las unidades fraseológicas}

No es fácil, a pesar de todo, elaborar una tipología diferenciada en el campo fraseológico, tal como señalan Ruiz-Gurillo (1997, p. 122) y García-Page (2008, pp. 103-115), al considerar que es complicado establecer una clasificación de unidades fraseológicas con una base sólida. Así se habla de sintagmas terminológicos, de compuestos yuxtapuestos, que están dotados de una estructura compleja y de idiomaticidad, aunque hay quien duda de que lo sean por la atonicidad del primer elemento; de colocaciones y construcciones con verbos de apoyo. Algunas de estas construcciones adquieren el rango de locuciones y de enunciados fraseológicos y otras, aun teniendo apariencia formal, no llegan a convertirse en expresiones fijas e idiomáticas por la posibilidad de admitir variaciones en su composición, por lo que algunos como Bosque (2001, pp. 20-21) y García-Page (2008, p. 12) niegan el carácter fraseológico, aunque puedan establecer equivalencias con palabras independientes, como sucede en 6. La caída de la economía brasileña aún no ha tocado fondo (El País, 1/12/15), donde el predicado "no ha tocado fondo" responde a una expresión fraseológica verbal enunciada de forma negativa y reforzada con el puntualizador temporal "aún" en lugar de usar el verbo pronominal "se resiste o aguanta".

\subsection{Relación entre las unidades fraseológicas verbales}

No puede dejarse de reconocer que los elementos que integran los predicados están sólidamente articulados, por lo que pueden ajustarse al sentido fraseológico unitario con que se emplean en el acto de hablar. La peculiaridad está en la combinación de $\mathrm{V}+\mathrm{SN}$ o SPrep. y de la utilización de verbos desemantizados, de apoyo o con valor de soporte léxicosintáctico, tal como funcionan "dar, saltar, plantar, meter y poner" en 7a. Rivera da un salto mortal contra Rajoy (El Mundo, 25/3/16); b. La lista que llevará el PSOE en Madrid salta por los aires $(A B C, 29 / 4 / 16) ;$ c. Sánchez planta cara al intento de relevarle al frente del PSOE (Libertad Digital, 30/12/15); d. Doce reglas gramaticales en las que solemos meter la pata (El Confidencial, 2/10/14); y e. El sustituto de Alonso pone en duda a la joya de Verstappen (El Confidencial, 1/4/16), expresiones verbales que adquieren un significado pragmático en el contexto mediante el procedimiento de metaforización utilizado: en 7a. para expresar que el sujeto enunciador "Rivera" se puede estrellar políticamente en esta ocasión por sus palabras dirigidas al otro enunciador "Rajoy"; en b. con el verbo "saltar" viene a decir que se cambia por completo la lista del PSOE; en c. la expresión "plantar cara" equivale a "desafiar"; en d. equivale la expresión a "equivocarse o confundirse"; y en e. la expresión formada por "pone (VApoyo) + en duda (Sprep)" es una colocación equivalente a "cuestionar o dudar". Según esto, la interpretación adecuada del sentido figurado de todas estas expresiones ponen de manifiesto la capacidad de los hablantes para identificar el significado en cada acto discursivo, teniendo en cuenta que la lengua es metafórica, lo que permite entender expresiones coloquiales en las que se produce una metaforización del predicado como sucede al decir 8a. Cómo poner 
a punto su coche (carro) sin salir de casa (Ecomotor, 7/3/13) a diferencia de lo que ocurre en b. Cómo hacer una revisión básica del coche (carro) (Motor, 10/6/15). Cabe decir que ambos enunciados tienen el mismo significado, el de "revisar el funcionamiento del coche", y utilizan un verbo de apoyo, respectivamente "poner y hacer", formando estructuras sintácticas analíticas, que podrían sintetizarse con la sustitución del predicado por el verbo "revisar". Así en a. se produce una formalización gramatical del predicado "poner a punto", en la que se elide alguna palabra relacionada con el mecanismo del motor, aunque el contexto permite saber que se refiere a la regulación de los dispositivos del coche (o carro) para que funcione bien, y en b. se recurre a la forma analítica "hacer la revisión", en la que se explicita "revisión", que equivale a la forma verbal sintética "revisar" o la fraseológica "poner al día o actualizar".

Asimismo los elementos de las colocaciones adquieren con frecuencia carácter metafórico, lo que contribuye a su combinación sintáctica y a la unidad semántica, aunque no está clara la diferencia con respecto a las locuciones. Aunque se trata de expresiones fraseológicas diferentes, muchas locuciones, caracterizadas por la fijeza y la idiomaticidad, se confunden con las colocaciones, que responden a procedimientos de contracción por exigencia léxico-sintáctica y no han alcanzado la fijeza de las locuciones, e incluso con fórmulas o expresiones formularias del tipo 9a. Los medios dieron por bueno el parecido razonable con el sospechoso que se apreciaba en las imágenes captadas en el aeropuerto (La Razón, 1/4/16), equivalente a una locución verbal con el significado de "aceptaron", o de b. Correa avala la investigación a 'Gürtel'4 y se ofrece a tirar de la manta (EcoDiario.es, 5/10/16 ), procedente de una tradición histórica de "desvelar públicamente que alguien era cristiano nuevo", que responde a una colocación "V+SN", equivalente a "tirar del hilo, de la cuerda", para indicar que se va a descubrir algo que por interés permanecía oculto; y también con expresiones tautológicas, como en 10. Tras las elecciones del 20-D, hemos insistido en que hay que ir paso a paso en la investidura para la presidencia del Gobierno. (El País, 9/12/15), donde el predicado formado por "ir + grupo nominal" reiterativo tiene valor de colocación con el significado de "actuar o avanzar con cautela". En cualquier caso, se trata de expresiones composicionales integradas. Por ello, lleva razón Ruiz-Gurillo (1997, pp. 74-81), al señalar que las UFS son “combinaciones estables idiomáticas”. De todos modos, la expresión fraseológica se caracteriza por la pérdida del significado particular de sus elementos para obtener un significado integral distinto. A ello contribuyen la desemantización de algunos de sus elementos, la fijación por restricción combinatoria y la adquisición del rasgo de idiomaticidad. Aun así, para García-Page (2008, pp. 103-115), también resulta difícil distinguir las diferentes formas de presentarse las unidades fraseológicas (UFS), aunque hay distintos grados de fijación en el proceso de formalización léxico-sintáctica.

\section{Las expresiones fraseológicas del español actual}

\subsection{Tipología de las unidades fraseológicas}

La mayoría de los paremiólogos, como Zuluaga (1980), Corpas-Pastor (1996), RuizGurillo (1997) y Wotjak (1998), distingue entre las expresiones idiomáticas, caracterizadas por su fijación e idiomaticidad ${ }^{5}$, y las unidades sintagmáticas nominales y verbales, caracterizadas por su fijación. Corpas-Pastor (1996, p. 52) establece tres tipos de unidades fraseológicas: locuciones, colocaciones y enunciados fraseológicos, pero cabe incluir otros tipos de formalizaciones o de expresiones composicionales integradas. 
De todos modos, Casares (1992, p. 182) ya definió las UFS como sintagmas fijos con valor categorial, al tiempo que las dividió en: 1) locuciones; 2) frases hechas, 3) refranes y 4) modismos. Entre las locuciones distingue las significativas -nominales adjetivas, verbales, participiales, adverbiales, pronominales y clausales y las conexivas - conjuntivas y prepositivas-. A todas ellas hay que añadir las interjectivas, a las que se refiere García-Page (2008, p. 21), del tipo 11. ¡qué está pasando con las tabletas! (El Mundo, 4/8/16), expresión exclamativa, en la que el locutor muestra su sorpresa por la caída de las ventas de tabletas, al tiempo que hace partícipe de esta información sorpresiva, de la que se infiere que es "insólito" en este momento, al interlocutor-lector con quien interactúa el periodista. Asimismo, Zuluaga (1980, p. 57) puntualiza que las participiales forman parte de las adjetivales.

En cuanto a las locuciones subordinadas, Corpas-Pastor (1996, pp. 109-110) considera que son unidades "restringidas para funcionar como elementos oracionales", por lo que "no pueden formar enunciados por sí mismas", ya que no contienen fuerza ilocutiva suficiente, como en 12. Otro cargando el peso de España sobre el lomo de Pedro Sánchez (Libertad Digital, 30 /12/15), que tiene sentido al introducir la expresión verbal "cargar el peso" dentro del contexto mediante el deíctico pronominal "otro", en correspondencia con otro deíctico "uno", para que la culpabilidad sobre la imposibilidad de formar gobierno recaiga en el enunciador "Sánchez". Aun así, Casares (1992, p. 182) añade que hay muchas locuciones que forman estructuras oracionales, como en 13. Carmona cree que el cambio en la portavocía "le costará caro al PSOE” (El Confidencial, 30/12/15). Esta expresión fraseológica tiene entidad propia puesto que adquiere valor de "enunciado fraseológico". En cualquier caso, las locuciones, señala Casares (1992, p. 168), se caracterizan por la inalterabilidad y la unidad de sentido de los componentes, puesto que son portadoras de un "significado unitario consabido", aunque han de estar ligadas a un contexto lingüístico y situacional adecuados.

\subsection{Las locuciones o unidades sintagmáticas verbales}

Dentro del grupo de las UFS, el grupo de las locuciones, equivalentes a un lexema o sintagma, es la clase más sistematizada y la que ha despertado un mayor interés entre los investigadores. Las locuciones no constituyen enunciados completos, sino que, más bien, funcionan como "elementos oracionales" y, como dice Koike (2001, p. 31), "se caracterizan por expresar su sentido idiomático en el marco de una estructura fijada", por lo que expresan su sentido idiomático dentro de una estructura fijada. Pero, aun siendo expresiones fijas, pueden presentar variantes. A este tipo de expresiones locucionales hay que añadir el concepto de unidades sintagmáticas verbales, término utilizado por Martín-Mingorance (1983, p. 211), para referirse a ciertas combinaciones fijas verbales, algunas de la cuales se construyen mediante el V + SN, como puede verse en numerosos usos del tipo: 14a. Obama: «Irán jamás echará mano de una bomba atómica» $(A B C, 18 / 1 / 16)$, donde se transcriben las palabras expresadas por Obama en forma de estilo directo utilizando la locución verbal "echará mano" por "recurrirá"; b. Cómo meter la pata por varios motivos con un Alonso que debe retirarse (El Confidencial, 3/2/16), que recurre a la locución verbal "meter la pata" por la forma sintética "equivocarse"; c. Mariano Rajoy tira la toalla y asume que Pedro Sánchez no le dejará gobernar (El Confidencial, 19/1/16), cuyo significado de esta locución verbal es "darse por vencido o derrotado" se utiliza en lugar de la forma sintética "abandona"; y d. Arrimadas teme que Iceta vuelva a las andadas (LD, 4/4/16 y El Confidencial, 4/4/16), locución verbal con el significado de "reincidir en una mala costumbre" en lugar de la forma sintética "repita". Como 
se observa, en todas estas expresiones el verbo ejerce una función primordial como "operador" sintagmático al que acompañan en a. un SN sin determinación; en b. y c. un SN constituido por det. + N; y en d. aparece un SPrep. con valor modal y temporal al mismo tiempo. Se trata, pues, de lexías pluriverbales o unidades sintagmáticas verbales - también denominadas 'expresiones fijas'-, consideradas como trozos de discurso previamente elaborados que se introducen como tales en nuevos discursos.

Para Zuluaga (1980, pp. 124 y 141), la definición de locución formulada por Casares puede ser conservada perfectamente como punto de partida y precisa que toda expresión idiomática es fija, por lo que la idiomaticidad presupone la fijación. Corpas-Pastor (1996, pp. 50-88) señala que las locuciones no constituyen enunciados completos ni actos de habla, sino que funcionan como elementos oracionales dotados de fijación interna, unidad de significado y fijación externa pasemática ${ }^{6}$ equivalentes a sintagmas. Esta idea es compartida por GarcíaPage (2008, pp. 27-33), al considerarlas como unidades fraseológicas constituidas por fijación, idiomaticidad e institucionalización.

\subsection{Las colocaciones}

Las colocaciones son combinaciones sintagmáticas composicionales, donde el colocativo delimita el significado del primer elemento o base sin lograr el carácter de idiomaticidad. A diferencia de las locuciones que no presentan flexibilidad sintáctica, las colocaciones admiten modificaciones, como dice Zuluaga (1980, p. 143). Además, las colocaciones se caracterizan por la composicionalidad semántica que no se da en las locuciones, puesto que, como apunta Koike (2001, p. 35), “[...] el significado de una colocación refleja los significados de sus partes constituyentes, mientras que la locución constituye un solo significado idiomático”.

\subsubsection{Proceso de formación de las colocaciones}

Las colocaciones se producen por la concurrencia de dos o más palabras frecuentes en el discurso, que suelen producirse por selección, restricción y composición gramatical, en combinaciones del tipo 15a. $\mathrm{N}+\mathrm{N}$ : casa cuartel; b. $\mathrm{N}+$ Adj.: sala mixta; c. Adj. + $\mathrm{N}$ : santas pascuas; d. N + Adv: cuenta atrás; e. N + SPrep: hoja de ruta; f. V + SN: La economía toca techo ante la ausencia de reformas por la parálisis política (El Confidencial. 19/1/16) y g. V + SPrep.: El músculo que tiene en vilo al R. Madrid (El Mundo, 28/4/16). De cualquier forma, como remarca Zuluaga (2002), las colocaciones son combinaciones de dos o más lexemas en relación hipotáctica fijadas por el uso social. Para otros, como Coseriu (1986) las colocaciones responden a "solidaridades léxicas" y Bosque (2001) apunta que no pertenecen a la fraseología, sino a la "interfaz léxico-sintaxis". De todos modos, las colocaciones son unidades fraseológicas formadas por dos unidades léxicas en relación sintáctica que por su fijación presentan restricciones de combinación establecidas por el uso con base semántica, como en: 16. Rosa Lladró, hija del mayor de los hermanos fundadores de la empresa, toma el mando y no descarta vender la firma (El País, 3/4/16), donde aparecen expresiones verbales formadas con verbos transitivos bivalentes que exigen dos argumentos relacionados con la

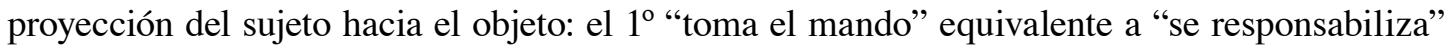
y el $2^{\circ}$ "vender la firma" que no es expresión propiamente dicha, sino una colocación, aunque el verbo va acompañado de un $\mathrm{SN}$ utilizado metonímicamente. 


\subsubsection{Clases de colocaciones}

Las colocaciones, según señala Corpas-Pastor (1996, p. 53), son "unidades fraseológicas que, desde el punto de vista del sistema de la lengua, son sintagmas completamente libres, generados a partir de reglas, pero que, a su vez, presentan cierto grado de restricción combinatoria determinada por el uso". Señala que hay dos tipos frecuentes según la categoría gramatical y la relación sintáctica de sus componentes:

1) el formado por SN + V, como en 17. Un ala del PP plantará batalla a Santamaría para impedir que logre el control del partido (Libertad Digital, 19/4/16), expresión verbal con un sujeto enunciador unido a un predicado, que opera con el procedimiento de colocación hasta constituir un enunciado libre con significado equivalente a "se enfrentará o se opondrá", y

2) el constituido por V $+\mathrm{SN}$ (objeto), del tipo 18. Se decía que Europa marcaba el camino como sistema regulado de orden internacional y con su modelo social (El País, 24/12/15), expresión que lleva también un sujeto enunciador "Europa", pero el predicado se forma con un verbo que se proyecta hacia $\mathrm{CD}$, por lo que viene a responder a una colocación con el significado equivalente a "guiaba, orientaba o controlaba".

Por su parte, Koike (2001, pp. 25-60) habla también de dos tipos esenciales de colocaciones:

1) Verbo + sustantivo o frase preposicional, como en 19a. El régimen sirio ha tomado cartas en el asunto. Para obtener el diploma universitario al finalizar los estudios hay que enlistarse previamente. Para obtener un pasaporte hay que pagar 380 euros, frente a los 20 que pagan las mujeres. (El País, 21/12/15), donde la expresión verbal formada por "V + SN" conforma una locución verbal metafórica con sentido generalizador equivalente significativamente a "se ha implicado"; y también mediante formas no sinonímicas que se neutralizan en el discurso con verbos como "dar, pegar, soltar, emitir + un grito" e incluso por metaforización en ejemplos del tipo b. ¿Vale la pena comprar gangas en Bolsa? (Libertad Digital, 8/3/16), expresión verbal que opera como colocación con el significado de "invertir o cotizar", como también sucede con tomar el pelo, una decisión, nota, parte, en consideración o levantar la voz, la mirada, la grada, las alfombras, sospechas; y

2) Sustantivo + adjetivo o adjetivo + sustantivo, como en 20a. Luz verde para destronar a Dilma Rousell (El País, 12/4/16), expresión nominal en que se elide el verbo "dar"; y sustantivo + sustantivo, como en b. En retirada: los fondos buitre salen de España con millonarias plusvalías (El Confidencial, 20/5/16)., expresión nominal metafórica e hiperbólica por colocación "los fondos buitre", referida a inversiones de capital riesgo en deuda cercana a la quiebra, por lo que de ella se infiere que es un negocio de mucho riesgo económico. A veces, la colocación proporciona un rasgo intensificador: batalla campal, cementerio nuclear, pueblo fantasma. No obstante, no hay que olvidarse de otras formas de combinación de las colocaciones.

\subsection{Los enunciados fraseológicos}

A diferencia de las locuciones, los enunciados fraseológicos constituyen para Zuluaga (1992, p. 129), por sí mismos, enunciados completos, por lo que "no necesitan un contexto verbal inmediato para constituir una expresión de sentido completo". Los define Zuluaga 
(1980, p. 192) como "secuencias autónomas de habla, cuya enunciación se lleva a cabo en unidades de entonación distintas", es decir, "son unidades de comunicación mínimas". Se caracterizan por la fijación y por tener significado referencial y autonomía textual. Muchas de ellas obedecen a situaciones culturales. En líneas generales, se corresponden con las paremias, que presentan fijación formal interna y externa, a la vez que coinciden con la estructura de las oraciones o frases completas, como en 21. Artur Mas se va y deja colocado a su 'fontanero' como conseller (El Confidencial, 12/1/16), donde la coordinación verbal recurrente constituye una unidad integradora equivalente a "privilegia" con un sentido claro inferencial para criticar el amiguismo.

Para Corpas-Pastor (1996, pp. 135-136), la paremia es equivalente al refrán y, a su vez, el hiperónimo de los subtipos de esta categoría, como los proverbios, los aforismos, las sentencias y los adagios. Por ello, las dos clases principales de enunciados fraseológicos son las paremias (refranes, eslóganes, consignas y citas) y las fórmulas rutinarias, que son enunciados prefabricados en determinadas situaciones comunicativas, como en 22. Los hijos de Conde en el ojo del huracán por ayudarle (El País, 12/4/16), que constituye un enunciado fraseológico en el que se elide el verbo "estar" conformando una expresión nominalizada a modo de expresión formularia.

\subsection{Frontera difusa entre las unidades fraseológicas}

Las expresiones fraseológicas presentan en el discurso formas muy variadas tendentes a integrar sus elementos para formalizar unidades fraseológicas. En realidad, se distinguen por el grado de integración de los elementos que las conforman, de tal manera que, mientras las locuciones se caracterizan por su fijación y logro de un significado integrador y unitario, las colocaciones no tienen totalmente integrados sus elementos, por lo que mantienen sus significados particulares y admiten variaciones.

De cualquier forma, Casares (1992, p. 185) incluye en la fraseología no solo las locuciones, sino también las unidades pluriverbales -frases proverbiales y refranes- además de los modismos, según su propia terminología. Por su parte, Ruiz-Gurillo (1998, p. 63) puntualiza que entre las expresiones del centro, donde incluye las locuciones, y las de la periferia, donde sitúa los refranes o expresiones figuradas, hay una frontera borrosa donde se combinan palabras formando sintagmas u oraciones, es decir, frases proverbiales, que unas veces estarán cerca de locuciones y en otras de los refranes. Precisamente en esta zona de convergencia podrían situarse las expresiones fraseológicas verbales, puesto que unas veces pueden conformar unidades fijas e idiomáticas, cuando forman locuciones o enunciados libres o expresiones formularias completas, o bien unidades semifijas o variacionales, cuando operan los procedimientos de restricción léxico-sintáctica en las colocaciones.

\section{Grado de formalización idiomática de las expresiones fraseológicas verbales en el discurso informativo del español actual}

\subsection{Proceso de formalización del predicado verbal}

Para explicar el grado de formalización de las unidades fraseológicas, además de tener en cuenta la fraseología y la paremiología, hay que recurrir a las aportaciones de la gramática, 
la semántica y la pragmática. Es un hecho que el predicado es el centro de la oración, por lo que el verbo, además de núcleo del predicado, es núcleo de la oración. Precisamente el verbo tiene la capacidad de seleccionar los complementos o argumentos, como explica Harris (1976, p. 26), al proponer que el predicado presenta una estructura formada por "predicado (operador) + argumentos" ", al igual que establece el funcionalista Tesnière (1966, pp. 238 y 259), aunque recurre a la terminología de actante y valencia. Las restricciones principalmente suelen ser de carácter sintáctico-semántico promovidas por exigencias de determinados verbos, pero también por algunos sustantivos y adjetivos.

De todos modos, se puede hablar de gradualidad a la hora de explicar el proceso de formalización léxico-semántico de las expresiones fraseológicas en el español actual. El predicado se comporta de acuerdo con las restricciones léxico-sintácticas impuestas por el verbo al funcionar como soporte o apoyo de la expresión en su conjunto. Así se nos presenta una amplia variedad de combinaciones gramaticales en las que operan procedimientos léxicosemánticos que proporcionan valores pragmáticos en función del contexto, tal como explica Ruiz-Gurillo (1997, pp. 91-102).

\subsection{Tipos de expresiones fraseológicas verbales en el discurso informativo}

El verbo es núcleo de predicado, pero también organizador sintáctico, portador semántico y centro del desarrollo temático que se proyecta en su estructura argumental. Además, por sí solo puede funcionar como oración, según explica Alarcos-Llorach (1994, p. 137), al combinarse un signo de referencia léxica (predicado) y otro complejo de referencia gramatical con significado de persona (sujeto gramatical). Por esta razón, normalmente el predicado se ensancha sintácticamente porque constituye una estructura argumental que incluye la función que ejercen las categorías y las proposiciones que inciden en su núcleo, donde pueden aparecer formalizaciones frecuentes entre el Verbo y sus complementos.

Puede afirmarse que en el español de todos los tiempos, y en el actual también, hay una tendencia a la formalización gramatical y a la lexicalización de formas analíticas, en general, y en el predicado, en particular. Esta proyección formalizadora del predicado verbal se produce normalmente al aglutinarse los complementos en torno al verbo en un proceso de fraseologización, que lleva a la fijación de sus elementos en expresiones fraseológicas de significado unitario, consideradas como "complejos sintagmáticos fijos", en palabras de RuizGurillo (1997, p. 103). Por ello, según el grado logrado de fijación y de idiomaticidad en cada situación productiva, se puede hablar, de acuerdo con Ruiz-Gurillo (1997, pp. 110-123), de diversos tipos de locuciones o expresiones fraseológicas verbales, entre ellos:

- Locuciones formalizadas pronominalmente con anomalías estructurales, pero dotadas de fijación e idiomaticidad y consideradas como prototipo de los sintagmas verbales fraseológicos, como en 23. Pero también se echa mano de esta fórmula en escenarios más difíciles, entre partidos directamente contrarios entre sí, que concitan la máxima rivalidad. Es el caso de la gran coalición alemana entre democristianos y socialdemócratas. (El País, 21/12/15), donde aparece una expresión idiomática verbal de carácter impersonal, correspondiente a una locución verbal fija, constituida por "V pronominal: se echa $+\mathrm{SN}$ : mano + de" utilizada en lugar de "se recurre".

- Locuciones verbales totalmente fijas e idiomáticas, por lo que no permiten alteraciones como en 24a. El tiempo dirá si el nuevo sistema es capaz de cumplir con las expectativas 
o si estamos condenados a dar un paso atrás. Estos son los riesgos de la nueva política (El País, 29/12/15) y b. Pablo Iglesias rompe la baraja para poner en evidencia las contradicciones del PSOE (El Confidencial, 23/12/15), donde los predicados de los enunciados a. y b. responden a expresiones fraseológicas verbales fijas e idiomáticas equivalentes a "retrocede" y a "corta radicalmente o por lo sano", puesto que los verbos exigen tales complementos en lo que no cabe variación ni cambio de orden de los elementos que integran la expresión.

- Locuciones verbales semiidiomáticas, dotadas de fijación, pero de escasa idiomaticidad. Se recurre a la metáfora y la hipérbole, como en 25. Ibarra, agredido por Bódalo (Podemos): No quiero echar más leña al fuego (El Confidencial, 6/4/16), expresión equivalente a "incrementar".

- Locuciones verbales escasamente idiomáticas: 26. Les pido a los partidos políticos que sean coherentes y no nos hagan perder el tiempo (referido al Rey) (La Razón, 27/4/16), expresión que puede formarse también sin determinante "perder tiempo" en oposición a "ganar tiempo".

- Locuciones verbales mixtas, que contienen una parte fija y otra idiomática, como en 27. Idealista echa el resto para tomar Tinsa y montar un imperio (El Confidencial, 1/4/16): en ambas expresiones actúa el procedimiento metafórico, la 1 "echa el resto" con un alto grado de formalización equivalente a "esforzarse al máximo" y la 2 a "montar un imperio" responde a una colocación donde el verbo "montar" se utiliza como sinónimo de "crear o fundar".

- Locuciones verbales meramente fijas, con un grado de cohesión alto y posibilidad de variación, como en 28. "Pidió lo más caro del menú, y luego se hizo la tonta; la dejé allí y me fui sin pagar" (El Confidencial, 3/4/16): la expresión está formalizada, pero admite otras combinaciones "la loca, la boba, valiente, interesante...", probablemente el vago significado del verbo "hacer".

- Locuciones verbales con variantes o alteraciones de sus componentes, como en 29. Tengo la impresión de que no: sus dirigentes parecen haber comprendido que el extremismo "chavista", que alentaban muchos de ellos, les cerraba las puertas del poder (de Vargas Llosa, en El País 17/12/15): ambas expresiones admiten variaciones, aunque la $2^{\text {a }}$ tiene un carácter más restrictivo por su sentido figurado.

- Unidades sintagmáticas verbales, que manifiestan una gran cohesión entre sus formantes, donde el componente verbal funciona como un verbo soporte: 30. El Rey abre la ronda de contactos con los 16 partidos registrados en el Congreso $(A B C, 18 / 1 / 16)$, donde el V + SN se integran por exigencia sintáctica y alcanzan un grado de formalización semántico-pragmática mediante la transposición metafórica de sus elementos al usar "abrir" por "iniciar".

- Colocaciones verbales formadas por componentes que manifiestan una alta coaparición debido a razones semánticas como la solidaridad léxica, como en 31. ¿Que va a venir a por la pasta? Puf, quilla, pues aquí también andamos a dos velas. Mejor quédate en tu tierra, aquí por no haber, no hay ni playa. (El Mundo, 29/3/16), donde las dos expresiones verbales constituyen colocaciones, puesto que los complementos se asocian sintáctica, léxica y semánticamente a los verbos sin que lleguen a adquirir valor idiomático por la posibilidad de admitir variaciones: "andamos a dos velas" por "andamos sin blanca" y "no hay playa" por "no hay nada o de nada". 


\section{Conclusión}

La fraseología atiende al conjunto de unidades fijadas que pertenecen al discurso repetido. En ella se integran las unidades pluriverbales o fraseológicas (lexías o expresiones fijas), que son las combinaciones de palabras que no se forman libremente por los hablantes, sino que forman parte del patrimonio sociolinguíístico de la comunidad de hablantes de la lengua. No basta conocer el significado de las expresiones fraseológicas sin más, sino que hay que saber las condiciones de uso que adquieren en cada contexto. Precisamente en la comunicación diaria aflora el proceso cognitivo-ideológico del hablante, como señala Van Dijk (1980), a través de las condiciones de producción social, los elementos de representación enunciativa y las estrategias argumentativas a las que recurre. Es necesario tener presente la relación existente entre enunciado y enunciación de acuerdo con la situación comunicativa, que viene dada por la selección léxicofraseológica y la combinación de categorías gramaticales adecuadas al tema a través de la elección de verbos adecuados al contexto comunicativo, a su restricción léxico-sintáctica y a la aportación de los componentes contribuyen a la formación de estructuras y esquemas sintácticos formalizados. Además de los elementos léxico-semánticos y sintácticos, hay que contar con la proyección pragmática que, en el discurso informativo, está asociado a la actualidad.

Es habitual la utilización de expresiones fraseológicas, sobre todo verbales, en el ámbito de la información, como reflejo de la lengua usual, basada en asociaciones léxicosemánticas y procedimientos de transposición semántica inherentes a la lengua. Y son muchas y variadas las formas con que se presentan las unidades fraseológicas, en las que concurren componentes lingüísticos y procedimientos léxico-semánticos en el proceso de fijación sintáctico-discursiva. Así se ha distinguido entre expresiones fijas, como las locuciones y enunciados fraseológicos, y las semifijas, como las colocaciones, caracterizadas por no haber logrado fijeza ni idiomaticidad y admitir variaciones. Dentro de las expresiones fraseológicas, se ha centrado el estudio en delimitar las unidades fraseológicas verbales donde el verbo adquiere función de soporte de la expresión para proporcionar el significado unitario junto con sus componentes. Así el procedimiento metafórico afecta al significado idiomático de las expresiones fraseológicas. Por ello, a través de la elección del verbo y de la combinación de los complementos que lo acompañan se identifica el conjunto de significados explícitos y los adicionales derivados del proceso inferencial asociado al contexto comunicativo.

\section{Notas}

1. El término «fraseología» proviene del griego frasis (expresión o frase) y logos (palabra o concepto). A diferencia de la fraseología, el concepto de paremia procedente del gr. $\pi \alpha \varrho o u \mu i ́ \alpha$ (proverbio) se utiliza también como sinónimos de refrán, adagio y sentencia.

2. Los ejemplos proceden de fuentes variadas de información, versión impresa y digital, como El País, El Mundo, ABC, La Razón, Libertad Digital (LD), El Confidencial, Marca, Ecomotor, Motor y EcoDiario.

3. Los enunciadores, siguiendo a O. Ducrot (1984, p. 205), son las voces a las que da entrada el locutor en el enunciado o discurso donde muestran sus puntos de vista.

4. Gürtel es una palabra alemana que significa "cinturón”, utilizada como nombre de un caso de corrupción política por la investigación policial española al asociar el significado "cinturón” con el apellido del presunto jefe de la trama investigada llamado Fernando Correa.

5. A diferencia de la idiomaticidad, la lexicalización se produce cuando un sintagma se convierte en unidad léxica, por lo que conlleva una cierta idiomaticidad o especialización significativa. Y la fraseologización es un proceso por el que, gracias a la fijación - parcial o total-se constituye una unidad fraseológica. 
6. Para Corpas-Pastor (1996, p. 24), la fijación pasemática, de acuerdo con Thun (1978), es "aquella fijación originada en el empleo de unidades lingüísticas según el papel del hablante en el acto comunicativo".

7. Los operadores responden a expresiones incompletas semánticamente, mientras que los argumentos son palabras que representan entidades.

\section{Bibliografía}

Alarcos-Llorach, E. (1994). Gramática de la lengua española. Madrid: E. Calpe.

Blanco-Escoda, X. (2000). Verbos soporte y clase de predicados en español. Lingüística española actual (LEA). 22/1, 99-118.

Bosque, I. (2001). Sobre el concepto de 'colocación' y sus límites. Lingüística Española Actual. 23 (1), 9-40.

Casares, J. (1992). Introducción a la lexicografía moderna. Madrid: C.S.I.C.

Cervera-Rodríguez, Á. (2013). Marcas lingüísticas de orientación argumentativa en actos de habla del español. Por M. J. Fernández-Leborans y L. Martínez-Falero (Eds.). Lingüística, retórica y teoría de la literatura. (57-70). Madrid: Arco libros.

Corpas-Pastor, G. (1996). Manual de fraseología española. Madrid: Gredos.

Corpas-Pastor, G. (2003). Diez años de investigación en fraseología: Análisis sintácticosemánticos, contrastivos y traductológicos. Madrid / Frankfurt am Main: Iberoamericana/Vervuert.

Coseriu, E. (1986). Las solidaridades léxicas. Principios de semántica estructural. (143-161). Madrid: Gredos.

Ducrot, O. (1984). El decir y lo dicho. Polifonía de la enunciación. Barcelona: Paidós.

García-Page Sánchez, M. (2008). Introducción a la fraseología española: estudio de las locuciones. Barcelona: Anthropos.

Harris, Z. S. (1976). Notes du cours de syntaxe. Paris: Le Seueil

Koike, K. (2001). Colocaciones léxicas en el español actual: estudio formal y léxicosemántico. Alcalá de Henares: Universidad de Alcalá de Henares.

Martín-Mingorance, L. (1983). Las unidades sintagmáticas verbales en inglés y español. Metodología de análisis. Tendencias actuales en las aplicaciones a la Lingüística. Actas I Congreso de Lingüística Aplicada. (211-221). Murcia: Universidad de Murcia.

Martínez-López, J. A. (1995). La fraseología del español. Acercamiento morfosintáctico, semántico y pragmático. Granada: Servicio de Publicaciones, Universidad de Granada.

Mellado-Blanco, C. (2004). Fraseologismos somáticos del alemán. Frankfurt am Main: Peter Lang.

RAE y Asociación de academias de la lengua española. (2009). Nueva gramática de la lengua española (NGLE). (Vols.1 y 2). Madrid: Espasa Calpe.

RAE y Asociación de academias de la lengua española. (2014). Diccionario de la lengua española. Madrid: Espasa Calpe. 
Ruiz-Gurillo, L. (1997). Aspectos de fraseología teórica española. Cuadernos de Filología, Anejo XXIV. València: Universitat de València.

Ruiz-Gurillo, L. (1998). La fraseología del español coloquial. Barcelona: Ariel.

Ruiz-Gurillo, L. (2001). Las locuciones en español actual. Cuadernos de la lengua española, 71. Madrid: Arco Libros.

Tesniére, L. (1966). Éléments de syntaxe structurale. Paris: Éditions Klinicksieck.

Thun, H. (1978). Probleme der Phraseologie. Tubingen: Niemeyer Verlag.

Van Dijk, T. A. (1980). Algunas notas sobre la ideología y la teoría del discurso. Semiosis. 5, 37-53. México: Universidad Veracruzana, Xalapa.

Wotjak, G. (1998). Estudios de fraseología y fraseografía del español actual. Frankfurt am Main, Vervuert: Lingüística Iberoamericana.

Zuluaga, A. (1980). Introducción al estudio de las expresiones fijas. Frankfurt: V. Peter Lang.

Zuluaga, A. (1992). Fraseología española. Holtus et ál (Eds.) Lexikon der romanistischen linguistik. (pp. 125-131) Tubingen: Niemeyer Verlag.

Zuluaga, A. (1997). Sobre las funciones de los fraseologismos en textos literarios. Paremia. 6, 631-640.

Zuluaga, A. (2002). Los enlaces frecuentes de María Moliner: observaciones sobre las llamadas colocaciones. Lingüística Española Actual (LEA). 24 (1), 97-114. 
